\title{
A COBRA E OS POETAS: UMA MIRADA SELVAGEM NA LITERATURA BRASILEIRA
}

Mário Geraldo Rocha

da Fonseca* *mgeraldof@gmail.com

Doutorado em Literatura Comparada pela Faculdade de Letras da UFMG.
RESUMO: Cobra é o termo principal da pesquisa, constituindo um conceito, um mapa e um personagem para defender a ideia de que, na literatura brasileira, existe uma linhagem de escritores que praticam o que a tese chama de escrita ofídica.

PALAVRAS-CHAVE: Cobra; literatura brasileira; literatura indigenista; literatura indígena; escrita ofídica.
ABSTRACT: Cobra (Snake) is the main term of this research This is why it starts by proposing that the term refers to a concept, a map and a character, in order to defend the idea that, in Brazilian literature, there is a lineage of writers who practice what this thesis calls ophidian writing.

KEYWORDS: Snake, wild reading, ophidian writing, Brazilian literature, literary representation of the indigenous, Indian literature. 


\section{1- APRESENTAÇÃo}

Os três níveis mencionados no resumo (conceito, mapa, personagem) são articulados pela maneira de proceder da Cobra que também recebe o nome de desvio. Dessa forma, a tese começa por definir o que é esse desvio, cotejando-o com alguns conceitos contemporâneos da teoria da literatura.

Nos primeiros capítulos, procura estabelecer os lugares desse desvio, notadamente, aquele onde foi alojado o conceito de "indigenismo literário", ainda muito usado para estudar certa linhagem de escritores brasileiros que assumiram a figura do índio como referência fundamental para construir as suas literaturas. Propõe, assim, outra maneira de trabalhar com a chamada "literatura indigenista" e com os diálogos que ela assume a partir da Semana de Arte Moderna, em 1922 Com tal procedimento, delineia também outra cartografia para a compreensão histórica dos chamados escritores indigenistas, e aplica o termo Cobra para sugerir um novo lugar que possa ser moldado não mais pelo referido conceito de "indigenismo literário", mas pelo olhar que está emergindo da chamada "literatura indígena", ou seja, pelos livros que estão chegando das aldeias.

A partir dos mitos compilados, estudados e difundidos por meio de livros produzidos pelos próprios indígenas, ou por eles juntamente com estudiosos da literatura e da antropologia, de modo particular dos índios kaxinawa (Acre) e sateré-mawé (Amazonas), a Cobra toma dimensão de um personagem que vai percorrer (mapa, história), analisar (teoria, método) e dialogar com o cânone literário indigenista e com suas invenções contemporâneas. Esse olhar da Cobra recebe também o nome de "mirada selvagem", uma visão que se esforça para assumir um "perspectivismo ameríndio", assim como é proposto por alguns estudiosos do campo da antropologia que se colocam nas sendas abertas pela filosofia "selvagem" de Nietzsche, Deleuze, Derrida, Agamben, além de Freud e Benjamin, entre outros.

\section{2- JUSTIFICATIVAS METODOLÓGICAS E TEÓRICAS}

Nos primeiros capítulos, a tese procura deixar claro que tanto o critério "indigenista" quanto aquele que supostamente sustentaria a autenticidade de uma voz "indígena" que os próprios escritores indigenistas tanto perseguiram são caminhos a serem evitados. De qualquer forma, aproveita os estudos daqueles que aplicam o conceito de "indigenismo" para entender alguns marcos fundamentais da literatura brasileira assim como daqueles que estão chamando atenção para o aparecimento do que consideram "literatura indígena", que ajuda a colocar em novo lugar a apropriação do mundo indígena feito por escritores brasileiros.

Assim, o estudo não desconsidera os dois termos, indigenista e indígena, como importantes para sustentar a moldura 
do quadro histórico e conceitual no qual vai se alinhar. A primeira palavra (indigenista) deixa uma marca fundamental para definir qual é o objeto da pesquisa. Esse gira em torno das obras que a crítica literária brasileira sempre considerou como parte do que chama de "indigenismo literário", ou seja, aqueles livros nos quais o referente "índio" é fundamental para a sua constituição e compreensão. É, portanto, um percurso que marca boa parte da literatura brasileira, começando, para muitos, com José de Anchieta, o primeiro dos escritores indigenistas; passa por Mário de Andrade, que volta aos escritos coloniais para compor as suas histórias; até chegar aos autores contemporâneos que vão buscar material no mundo indígena para construir suas literaturas.

No que diz respeito à segunda palavra ("indígena"), retira preciosas indicações metodológicas, uma vez considerado o fato de que, nas histórias indigenistas, o mito indígena, de alguma maneira, tinha sido levado em consideração, apesar de saber que, ao se apropriar dele, o escritor estaria caindo na armadilha da crença do "autenticamente indígena".

Dessa forma, um termo que desse conta dos dois lugares, mas que não se colasse a nenhum deles, tornou-se necessário. Percebeu-se que a "voz indígena" que se infiltrava nas histórias indigenistas, agora dispensando a obrigação de ser "autêntica", era, no entanto, fundamental para que tal história pudesse ser contada, lida e estudada. Deslocando o foco moldado por certa obrigatoriedade crítica de mapear a figura concreta do índio nos livros indigenistas, tornou-se possível ouvir aquela "voz" não mais na sua condição, por assim dizer, antropológica, e sim como uma marca realmente literária; ou seja, como uma invenção que não podia ser ouvida, no entanto, sem que se levasse em conta que o referencial indígena com o qual ela claramente se identificava era um elemento necessário para que tal "voz" se traduzisse realmente em literatura.

A "voz indígena" que se ouvia no texto indigenista, portanto, é a sua própria condição de possibilidade para quem quisesse trabalhá-la literariamente. Tirada do vocabulário filosófico moderno e contemporâneo, especialmente daquele ligado a postulações kantianas, tal noção veio, na tese, ajudar a sintonizar a leitura do cânone indigenista brasileiro com as teorias filosóficas, que, por sua vez, foram incorporadas aos estudos literários para que dessem conta dos desafios colocados pela literatura contemporânea.

Dessa forma, os mitos indígenas passaram a assumir um papel relevante na identificação daquela "voz" que emergia das obras literárias indigenistas. Para tanto, contou-se com um vasto material escrito pelos próprios índios, e que, aos poucos, vem assumindo a devida relevância no cenário literário brasileiro. Neles, os índios que, até então, eram vistos como alheios ao mundo da escrita passaram a colocar no 
1. Expressão que os italianos usam quando desejam enfatizar uma afirmação. papel aquilo que, na verdade, sempre esteve escrito, mas da forma que era possível em um mundo no qual a oralidade portanto, a "voz" - foi encontrando a sua maneira específica de se inscrever e criar, assim, uma vera e propria ${ }^{1}$ escrita.

Por esse novo foco, os dois mundos, muito bem representados pelo encontro dos colonizadores europeus com os índios americanos, ocorrido no século XVI, passam a perceber que, mesmo que não deixassem de se ver como estranhos, mantiveram, ao longo dos séculos, certa intimidade que não é possível ignorar se levarmos em conta que foi dessa convivência que realmente surgiu a vertente indigenista que marca indelevelmente a literatura do continente. $O$ modo de falar indígena, portanto, vai ser uma maneira muito própria para que os escritores latino-americanos pudessem ouvir aquela "voz" que sempre perseguiram, pensando em traduzir em literatura o modo de viver do homem americano.

De maneira especial, os escritores que se colocaram a tarefa de ouvir a "voz nativa" e de com ela construir uma lingua que desse conta de expressá-la foram buscar nos mitos indígenas os elementos para sustentar tal projeto. Alguns chegaram mesmo a ir aonde tal "voz" estaria disponível in loco, como foi o caso de alguns modernistas paulistas que, na década 1920, se dirigiram para a Amazônia a fim de encontra aquele "Brasil profundo" que gostariam de retratar. Mesmo esses não dispensaram as pesquisas dos antropólogos, uma vez que a tendência que marcou os estudos antropológicos do século XIX, quando a antropologia, como matéria acadêmica, dava os seus primeiros passos no país, considerava as línguas nativas o elemento mais esclarecedor da vida dos povos indígenas, e a sua maneira particular de falar e de traduzir tal fala em mitos e histórias como elementos fundamentais para se entender a cultura ameríndia.

Porém, os escritores indigenistas, que não puderam contar com o material antropológico, se valeram de textos que, nos séculos anteriores, foram escritos por aqueles que, de alguma forma, tiveram contato com a vida dos índios. Portanto, já fica dada a indicação de que, muitos dos livros produzidos por escritores indigenistas nasceram do trabalho que eles tiveram de ler e pesquisar no material colhido por viajantes que passaram pelo Brasil nos dois primeiros séculos de colonização, deixando suas impressões e estudos em vários tipos de relatos. Como sustenta o segundo capítulo da primeira parte da tese, os relatos de viagem são fundamentais para se entender a história da literatura brasileira, de modo especial, o momento em que se colocou o desafio de encontrar uma "voz" realmente nacional, o que ocorreu no início do século XIX.

Embora os dados acima mencionados sejam historicamente incontestáveis, poucos estudos, porém, se voltaram no sentido de aproveitar a pesquisa sobre os mitos indígenas para moldar um novo olhar em relação às obras que pedem 
esse material para serem efetivamente compreendidas e contextualizadas. Assim, para incorporar tais estudos, foi necessário ir construindo um lugar que não dependesse nem do viés indigenista nem daquele que se acreditou ser uma "voz" autorizada do mundo indígena, mas de como os escritores brasileiros, ao se voltarem para o material indígena, fizeram uma apropriação que indicava alguns dos procedimentos mais importantes para se entender a formação da literatura brasileira como tal.

\section{3- EMBASAMENTO TEÓRICO}

Alguns dos mitos indígenas mais conhecidos, principalmente os de proveniência amazônica, evidencia uma vertente que não se pode ignorar, uma vez que não se trata de ficar em apenas um mito, mas em procedimentos mais gerais, que podem sim, ser aproximados das histórias indigenistas.

Como se sabe, existem vários personagens fortes na mitologia amazônica, e alguns deles foram incorporados no corpus da pesquisa, como, por exemplo, a tucandeira e o papagaio, preguiça, a onça. Um, porém, parece catalisar as forças que nela se apresentam. O seu nome não deixa de ser imediatamente invocado quando se pensa no imaginário que o Brasi e o mundo têm da região amazônica. Trata-se da CobraGrande, que, em alguns casos, tornou-se a própria indicação do imaginário indígena e caboclo. Dela, a mais conhecida das histórias remete à sua aparição na figura de um ser que só poderia mesmo emergir dos descomunais rios da região, com suas forças titânicas, assim como são apresentadas por alguns estudos geográficos. Por isso, para muitos, aquela figura se apresenta na sua dimensão monstruosa, capaz de destruir tudo o que encontra pela frente. Ao se mover, a Cobra-Grande provoca terremotos e, se é noite, pode ser confundida com um imenso navio, com uma enorme boca na proa.

No entanto, existe uma vertente que trabalha o mito da Cobra por outro caminho, que, diria, transita mais perto do cotidiano daqueles que moram nas margens dos rios amazônicos. Uma vertente "menor", para usar um termo de Deleuze e Guattari para especificar um tipo de literatura que nasce do desvio daquela que usa a língua no sentido padrão, como veremos adiante. ${ }^{2}$

A tese apresenta dois exemplos daquele tipo de narrativa. Nesse caso, também condição de possibilidade é uma expressão que precisa ser levada em consideração, uma vez que, mais do que os terríveis modos de proceder de um temido monstro, a figura do animal é vista como um elemento no qual se encontram articulações que ajudam a população ribeirinha a desenvolver maneiras de expressar a sua forma específica de se relacionar com a natureza. Logo, nos mitos kaxinawa e sateré-mawé , estudados no "Intermeio" da tese, busca-se
2. Cf.: DELEUZE; GUATTARI. Kafka: por uma literatura menor, 1997.
EM TESE
BELO HORIZONTE
v. 19
N. 2
AG0.-OUT. 2013
FONSECA. A cobra e os poetas: uma mirada selvagem na literatura brasileira $\quad$ p. 217-225 
observar como essas narrativas oferecem um aporte de situações que indicam as saídas que os homens da região encontram para lidar com uma natureza que, de tão exuberante e poderosa, chama constantemente aos desvios (ou "furos", como o caboclo chama alguns cursos d'água que encurtam as distâncias entre, por exemplo, dois rios maiores), para não serem tragados por ela.

Assim, a Cobra, mais do que o monstro que habita algumas histórias que a ela se referem como um ser tão poderosamente incontrolável, como tende a ser vista a natureza amazônica, é, nesta tese, signo da esperteza, da qual estão recheados os mitos indígenas e a leitura que deles fizeram alguns escritores brasileiros. A maneira como os índios e caboclos observam o animal se movimentando no seu habitat, diria, natural, diz do movimento que gostaria de atribuir a ela na tese. Algo que, diante dos obstáculos que se apresentam no seu caminho, mais do que destruí-los propriamente, procura deles desviar-se, não os ignorando, mas também não se submetendo a seus caprichos.

Por isso, o conceito de desvio, inicialmente apresentado na maneira como foi usado pelos formalistas para refletirem a respeito das especificidades do texto literário, será de grande valia. Lembrando, porém, que a relação desvio/norma, à qual ficou muito vinculada aquela noção formalista, vai ser problematizada por outros conceitos, como fora (Blanchot), dobra (Deleuze), passagem (Benjamin), que podem ser situados no mesmo campo semântico de desvio, mas ampliando o seu alcance. Isso indica que o que vou chamar, mais adiante, de método da Cobra, na verdade, é apenas a maneira que encontrei para dizer que, na compreensão da mitologia amazônica, a paisagem da região não pode ser um elemento dispensável; assim, a Cobra, além daquele personagem do qual falei anteriormente, também quer traduzir uma visão de mundo que leva em consideração a condição do lugar onde é formulada.

De fato, quem já teve a oportunidade de navegar pelos rios amazônicos sabe o que significa "serpentear", uma das expressões que se usa para falar do espaço ocupado pelos rios, que vão mata adentro e, muitas vezes, encontram-se consigo mesmos, dando uma volta na própria floresta. Por isso alguém disse: "O rio comanda a vida" - título, por sinal, de um dos livros que melhor deu conta de observar como a prevalência dos cursos d'água determinam a vida (e a morte) na Amazônia. Na obra em questão, de 1973, o sociólogo acreano Leandro Tocantins mostra o contato muito estreito do homem que mora nas margens dos rios com o animal que melhor define a sua força vital, a cobra. Um outro atencioso observador da vida amazônica, o poeta Thiago de Mello, querendo definir a sua região, a chamou de "pátria da água".
3. Imagem muito frequente nos livros Mormaço na floresta (1981) e Amazonas: pátria da água (2006). 
Assim, será preciso falar em "mapa”, e, com isso, não apenas para falar de um recurso que traduziria em imagem um determinado lugar, geograficamente estipulado. Tratase também da cartografia que a tese constroi, ao assumir o imaginário da Cobra como meio para viajar pela história da literatura brasileira. Isso ficará mais claro no segundo capítulo da primeira parte, mas já se torna necessário deixar claro que, sem a noção de viagem, como aquela que está muito presente nos mitos indígenas, não seria possível cogitar um novo lugar de onde observar a literatura indigenista e, por meio dela, oferecer alguns elementos para se pensar a literatura brasileira de modo geral.

Por isso, para a tese, não é dispensável todo material antropológico no qual a figuração da Cobra é vista na tentativa de se encontrar alguns vetores que possam ajudar a compreender não apenas os mitos em si, mas também a própria visão de mundo que neles se apresenta. Desse modo, a corrente de estudos antropológicos que ficou conhecida por ter ido à procura de um "pensamento selvagem" é necessária para a pesquisa. Isso se deve ao fato de que os estudiosos alinhados a essa vertente reconheceram que os mitos indígenas, além da enorme carga de ficcionalidade que traduzem nas histórias a que dão forma, carregam em seu bojo um potencial muito grande para formular uma vera e propria filosofia na perspectiva indígena.
Para os estudiosos do "pensamento selvagem", os personagens que aparecem nas narrativas míticas podem ser um referencial primoroso para elaborar conceitos que ajudam a entender melhor o mundo indígena e a relação que estabeleceram com a literatura brasileira, por meio de livros que a elas fazem referência. $O$ estudo incorpora tal perspectiva na formulação que tem como base o significante Cobra. Esse, então, será, além dos mencionados personagem e mapa, também um conceito, o qual coteja com alguns termos da filosofia contemporânea que ajudam a selar a parceria entre os estudos dos mitos e elementos da teoria literária contemporânea.

Dessa parceria, nasce o termo que, de fato, entrou para o título da tese, depois de ter passado por duas tentativas ${ }^{4}$ Como dito, nem "indigenista", nem "indígena", mas Cobra ou seja, o nome de um animal selvagem que, além de remeter aos mitos indígenas, também faz referência ao mundo do qual eles provêm, assim como é possível de compreender através de estudos antropológicos que sobre ele foram feitos. O termo "selvagem", usado por alguns antropólogos que foram à procura de parâmetros pelos quais pudessem estudar o mundo indígena, na tese, é utilizado em uma posição que está no meio do caminho, entre aqueles dois termos que não podemos evitar, mas com os quais precisamos tomar cuidado.
4. Quando da apresentação para o programa de pós-graduação da Faculdade de Letras da UFMG, o projeto chamou-se "O xamã e os poetas: indigenismo errante na poesia brasileir contemporânea". Em um segundo momento, que coincidiu com o exame de qualificação, 0 título passou a ser: "O xamã e os poetas: uma mirada indígena na literatura brasileira". 
Com o termo selvagem, pode dizer do lugar que realmente o enunciador da pesquisa procura ser identificado, já que não pretende fazer apologia do "indigenismo" e, muito menos, se investir de uma "voz" indígena. Sendo um trabalho com pretensões analíticas e teóricas, não esconde, no entanto, a sua profunda simpatia pelo o modo dos índios de fazer "literatura”. Mistura, portanto, a ficcionalidade que é sugerida pelos mitos com termos da filosofia e da teoria literária contemporâneas.

\section{4- CONCLUSÃO}

A viagem em companhia da Cobra que a tese propõe, portanto, tem como objetivo observar, a partir dos livros que marcaram a história do indigenismo na literatura brasileira, os processos criativos que tornaram tal literatura possível. Sendo um personagem tirado dos mitos, portanto, com forte carga de inventividade, o proceder da Cobra é a maneira para analisar como, ao incorporarem os mitos indígenas nas suas obras, os escritores indigenistas deixaram-se, diria, "contaminar" pelo proceder que se pode observar nos próprios mitos. Além disso, foram mais longe: com base no mito do qual se haviam apropriado, criaram uma obra que diz muito do proceder literário brasileiro e latino-americano. Sem isso, não seria possível formular a hipótese de que tal literatura tem uma singularidade que a define e marca o seu modo próprio de ser e estar no conjunto do que se chama "literatura mundial".
A Cobra, por conseguinte, tem, na tese, um objetivo bem específico ao se movimentar pela literatura brasileira: focar nos procedimentos literários que tornaram possível o diálogo com os mitos indígenas. Por isso, são de grande valia alguns conceitos que, na reflexão a respeito da literatura contemporânea, procuram levar em conta os procedimentos especificamente literários. Para tanto, alguns filósofos contribuem de maneira fundamental. Falo de modo especial daqueles que pensaram na forma de compreender o que chamam de "ato criativo", inclusive para se entender não apenas a literatura e a arte, mas também a maneira humana de pensar. De maneira particular, tenho em mente a filosofia de Nietzsche, que observou de forma aguda como, nas palavras de um dos seus intérpretes, "conhecer é criar". ${ }^{5}$ Para dar conta de considerar isso, o filósofo alemão tornou-se um daqueles que melhor refletiu a respeito do que chama de "potencialidades criativas do pensamento", tema que vou aproveitar para aproximar certos procedimentos observáveis na escrita nietzschiana, que levou alguns comentadores a considerarem-na "selvagem", ${ }^{6}$ logo, podendo, por sua vez, ser aproximada de narrativas indígenas.

Considera que uma das potencialidades embutidas no conceito Cobra mostra como alguns escritores exploraram (e exploram) bem a força criativa que está presente nos mitos indígenas, em especial aqueles relacionados com o mundo
5. Cf.: FOGEL. Conhecer é criar: Nietzsche, 2003

6. Falo de alguns livros de Roberto Machado e de Oswaldo Giacoia Júnior, apenas para citar alguns que são comentados na tese. 
aquático. Por isso, sustenta a tese de que, na literatura brasileira, existe uma linhagem de escritores que podem ser considerados ofídicos. Logo, fala em uma escrita ofidica, exatamente para mostrar como o imaginário da Cobra, assim como aparece nos mitos indígenas amazônicos, ajuda a compreender procedimentos literários que são muito singulares da literatura produzida no Brasil e em alguns países da América Latina.

\section{REFERÊNCIAS}

DELEUZE, Gilles; GUATTARI, Félix. Kafka, por uma literatura

menor. Tradução de Júlio Castañon Guimarães. Rio de Janeiro: Imago, 1977.

FOGEL, Gilvan. Conhecer é criar: um ensaio a partir de Friedrich Nietzsche. São Paulo: Discurso Editorial, 2003.

GIACOIA JÚNIOR, Oswaldo. Nietzsche. São Paulo: Publifolha, 2000

MELLO, Thiago. Faz escuro, mas eu canto. In Vento geral (1951-1981): doze livros de poemas de Thiago de Mello. Rio de Janeiro: Civilização Brasileira, 1984, p. 209-265.

MELLO, Thiago. Mormaço na floresta. In: Vento geral (1951-1981): doze livros de poemas de Thiago de Mello. Rio de Janeiro: Civilização Brasileira, 1984, p. 381-467.

MACHADO, Roberto. Nietzsche e a verdade. Rio de Janeiro: Graal, 1999. 